\title{
ДИАГНОСТИКА НЕДОСТАТОЧНОСТИ КОРЫ НАДПОЧЕЧНИКОВ ПОСЛЕ ОПЕРАЦИИ ПО ПОВОДУ КОРТИКОСТЕРОМЫ
}

\author{
Буйнова М.О., Ворохобина Н.В., Великанова Л.И.
}

\author{
ФГБОУ ВО «СЗГМУ им. И.И. Мечникова» Минздрава России, Санкт-Петербург
}

ЦЕЛЬ: оценить состояние гипофизарно-адреналовой системы у больных после операции по поводу кортикостеромы для оптимизации тактики послеоперационного ведения.

МАТЕРИАЛЫ И МЕТОДЫ: обследовано 143 пациента (43 мужчины и 100 женщин) в возрасте 51,3 $\pm 14,1$ лет с инциденталомами надпочечников и 27 здоровых лиц (группа контроля) в возрасте $48,5 \pm 5,7$ лет. По результатам обследования у 18 пациентов в возрасте 48,1 18,3 лет диагностирован синдром Кушинга (СК) и проведена односторонняя тотальная адреналэктомия. У 43 пациентов в возрасте $53,7 \pm 3,2$ лет выявлена автономная секреция кортизола (АСК). 20 больным из данной группы также проведена односторонняя тотальная адреналэктомия в связи с большим размером образования или наличием признаков возможной злокачественности по данным лучевой диагностики. С 1 по 7 день после операции, в раннем послеоперационном периоде (РПП), проводился анализ клинической картины, объективных, лабораторных и инструментальных данных. Данные обследования больных с СК и АСК после операции были сопоставлены с результатами дооперационного обследования и с соответствующими показателями группы контроля (ГК).

РЕзУЛЬТАТЫ: в РПП пациенты с СК были разделены на 2 группы в зависимости от уровня кортизола в 9 ч. по данным имуноанализа (ИА). Первая группа (СК1) - пациенты с СК, у которых уровень кортизола (К) в 9ч в сыворотке крови был меньше нижних референсных значений ГК (<70 нмоль/л), во второй группе (СК 2) уровень К находился в области референсных значений ГК (>300 нмоль/л). У больных СК1 получено снижение уровней кортизола в сравнении с ГК по данным ИА $(p=0,0001)$ и ВЭЖХ $(p=0,006)$. В РПП у больных CK 1 снижены уровень альдостерона $(p=0,02)$ и ренина $(p=0,02)$ в сравнении с ГК, а у пациентов с СК 2 уровень альдостерона и ренина не отличались от ГK ( $p=0,8)$. У больных СК1 в РПП по данным ВЭЖX уровень В не отличался от уровня В в ГK $(p=0,1)$, а у пациентов СК2 был повышен в сравнении с уровнем В в ГК (p=0,02). Результаты ВЭЖХ у больных СК 1 и СК 2 в ДОП были сравнены с ГК. Уровень F и соотношение F/E в сыворотке крови, ЭМ UFF, UFE и U18-OHВ увеличены у больных CK 1 и СK 2.У больных CK1 в ДОП дополнительно увеличены уровни B, S, 18-OHB, соотношение B/A в сыворотке крови и ЭМ U18-OHB и U6ß-OHF в сравнении с ГК. Уровень S в сыворотке крови выше у больных СК 1 в сравнении с СК 2 в ДОП. Уровни гормональных показателей в крови и моче в ДОП по данным ВЭЖХ (В более 3,2 нг/мл, 18-ОНВ

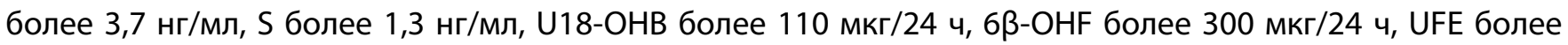
250 мкг/24 ч) с чувствительностью и специфичностью более $80 \%$ предсказывали глюкокортикоидную недостаточность у больных с СК. В РПП у больных с АCK уровни F, E, B, S, A не отличались от ГК (p>0,05). Получено увеличение уровня $18-\mathrm{OHB} \mathrm{в} \mathrm{сыворотке} \mathrm{крови}(p=0,02)$ и его ЭМ $(p=0,04)$. Однако у 5 пациентов с ACK и злокачественным потенциалом 1-3 балла по шкале L.M.Weiss в PПП снижены уровни F, E и S, увеличен уровень 18-ОНВ в сыворотке крови. В ДОП у данных больных повышены уровни В в сыворотке крови и соотношения В/А в сравнении с ГК и показателями в РПП. Уровень В более 8,0 нг/мл в сыворотке крови по данным ВЭЖХ в ДОП со 100\% чувствительностью и 92,3\% специфичностью $(A \cup C=0,92)$ предсказывал глюкокортикоидную недостаточность у больных с АСК в РПП.

ВЫВОды: признаки недостаточности коры надпочечников в раннем послеоперационном периоде получены у $72 \%$ больных синдромом Кушинга и у $20 \%$ больных с автономной секрецией кортизола по данным иммуноанализа и высокоэффективной жидкостной хроматографии. Повышение в дооперационном периоде уровня В в сыворотке крови у всех больных, увеличение уровней S и 18-ОНВ в сыворотке крови, экскреции с мочой свободного кортизона, 18-OHB и U6ß-OHF у больных синдромом Кушинга указывают на развитие недостаточности надпочечников в раннем послеоперационном периоде.

КЛЮЧЕВЫЕ СЛОВА: недостаточность коры надпочечников; дооперачионный период; ранний послеоперационный период; синдром Кушинга; автономная секреция кортизола; высокоэффективная жидкостная хроматография. 